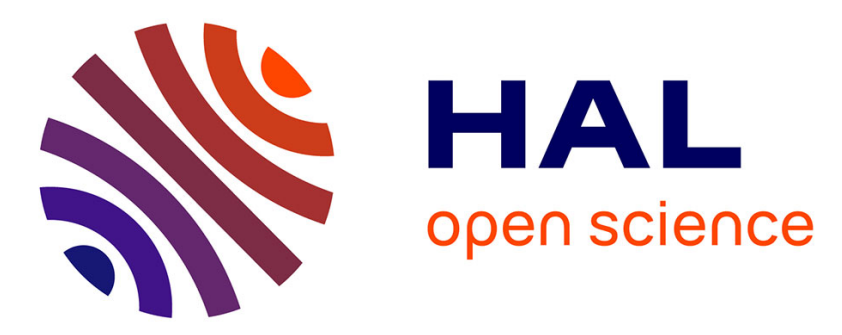

\title{
On-chip grating coupler array on the SOI platform for fan-in/fan-out of multi-core fibers with low insertion loss and crosstalk
}

Yunhong Ding, Feihong Ye, Christophe Peucheret, Haiyan Ou, Yutaka Miyamoto, Toshio Morioka

\section{- To cite this version:}

Yunhong Ding, Feihong Ye, Christophe Peucheret, Haiyan Ou, Yutaka Miyamoto, et al.. On-chip grating coupler array on the SOI platform for fan-in/fan-out of multi-core fibers with low insertion loss and crosstalk. 40th European Conference on Optical Communication (ECOC 2014), Sep 2014, Cannes, France. paper We.1.1.3, 10.1109/ECOC.2014.6964081 . hal-01069400

\section{HAL Id: hal-01069400 https://hal.science/hal-01069400}

Submitted on 29 Sep 2014

HAL is a multi-disciplinary open access archive for the deposit and dissemination of scientific research documents, whether they are published or not. The documents may come from teaching and research institutions in France or abroad, or from public or private research centers.
L'archive ouverte pluridisciplinaire HAL, est destinée au dépôt et à la diffusion de documents scientifiques de niveau recherche, publiés ou non, émanant des établissements d'enseignement et de recherche français ou étrangers, des laboratoires publics ou privés. 


\title{
On-chip Grating Coupler Array on the SOI Platform for Fan-in/Fan-out of Multi-core Fibers with Low Insertion Loss and Crosstalk
}

\author{
Yunhong Ding ${ }^{(1)}$, Feihong $\mathrm{Ye}^{(1)}$, Christophe Peucheret ${ }^{(2)}$, Haiyan $\mathrm{Ou}^{(1)}$, \\ Yutaka Miyamoto ${ }^{(3)}$, and Toshio Morioka ${ }^{(1)}$
}

(1) DTU Fotonik, Department of Photonics Engineering, Technical University of Denmark, 2800 Kgs. Lyngby, Denmark, yudin@fotonik.dtu.dk

(2) FOTON Laboratory - CNRS UMR 6082, ENSSAT, University of Rennes 1, 22300 Lannion, France.

(3) NTT Network Innovation Laboratories, NTT Corporation, Yokosuka, Kanagawa, 239-0847, Japan.

\begin{abstract}
We design and fabricate a compact multi-core fiber fan-in/fan-out using a fully-etched grating coupler array on the SOI platform. Lowest coupling loss of $6.8 \mathrm{~dB}$ with $3 \mathrm{~dB}$ bandwidth of $48 \mathrm{~nm}$ and crosstalk lower than $-32 \mathrm{~dB}$ are demonstrated.
\end{abstract}

\section{Introduction}

The communication capacities of single mode fiber (SMF)-based optical transmission systems have been rapidly pushed towards their theoretical limit $^{1}$ by the fast growing traffic demand these years. Space-division multiplexing (SDM) based on multi-core fibers (MCFs) has been demonstrated to be a promising technology to further increase the communication capacity over a single fiber. By introducing uncoupled multiple cores in a single fiber, large communication capacities with long transmission distances have been reported ${ }^{2-6}$. One important component for MCF based SDM technology is a compact and efficient MCF fanin/fan-out (FI/FO) device with low coupling loss and large bandwidth. Several FI/FOs schemes have been proposed, including free space based coupler $^{6}$, three dimensional (3D) waveguides fabricated by ultrafast laser inscription ${ }^{7}$, physical-contact type $\mathrm{Fl} / \mathrm{FO}^{8}$, etc.

In this paper, we demonstrate a compact onchip 7-core fiber FI/FO using a fully-etched apodized grating coupler array on the silicon-oninsulator (SOI) platform, as shown in Fig. 1. Coupling loss as low as $6.8 \mathrm{~dB}$ with $3 \mathrm{~dB}$ bandwidth of $48 \mathrm{~nm}$ and less than $3 \mathrm{~dB}$ coupling loss variation between spatial channels were achieved. It is a promising technology thanks to its potential for integration of many $\mathrm{Fl} / \mathrm{FO}$ couplers and other functionalities such as switching matrices on the same chip.

\section{Grating coupler design}

An SOI chip enabling coupling from 7 standard SMFs (SSMFs) to one 7-core MCF using grating couplers is proposed, as shown in Fig. 1. The grating couplers, identical at both ends of the circuit, are designed and optimized for coupling to SSMFs. A silica-clad fully-etched silicon photonic crystal (PhC) grating coupler with bonded bottom mirror on a silicon carrier wafer is proposed, as depicted in Fig. 2. There are

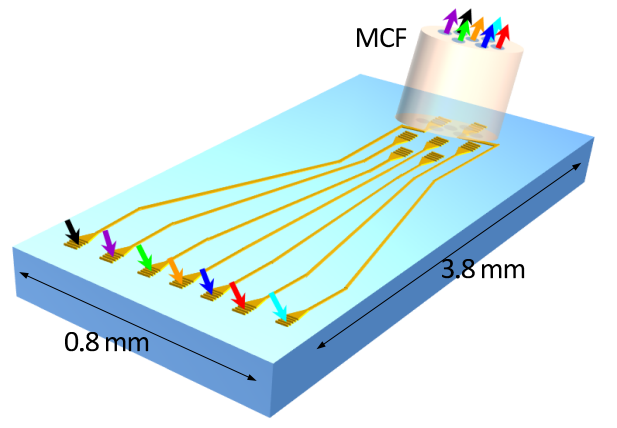

Fig. 1: Schematic of the grating coupler-based FI/FO.

three advantages for the proposed design. Firstly, the fabrication process can be simplified by using a fully-etched design so that the grating couplers can be simultaneously fabricated with the rest of the circuit ${ }^{9}$. Secondly, a high coupling efficiency (CE) can be achieved thanks to the bonded metal mirror. Finally, both upper and lower cladding thicknesses can be precisely optimized by bonding technology. The thickness of the top silicon device layer is $250 \mathrm{~nm}$. In order to achieve an apodized grating coupler diffracting a Gaussian field profile, artificial materials are introduced for the scattering units, with refractive indices $n_{i}$ and lengths of scattering units $l_{i}$ changed along the grating ${ }^{9}$. $\mathrm{SiO}_{2}$ is used as upper and lower cladding material with thicknesses of $h_{u}$ and $h_{d}$,

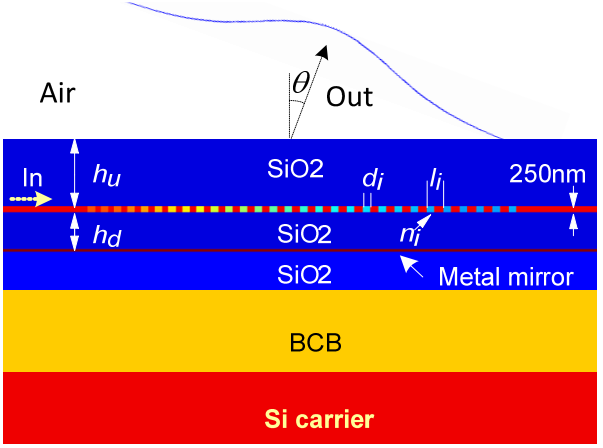

Fig. 2: Structure of the grating coupler. 

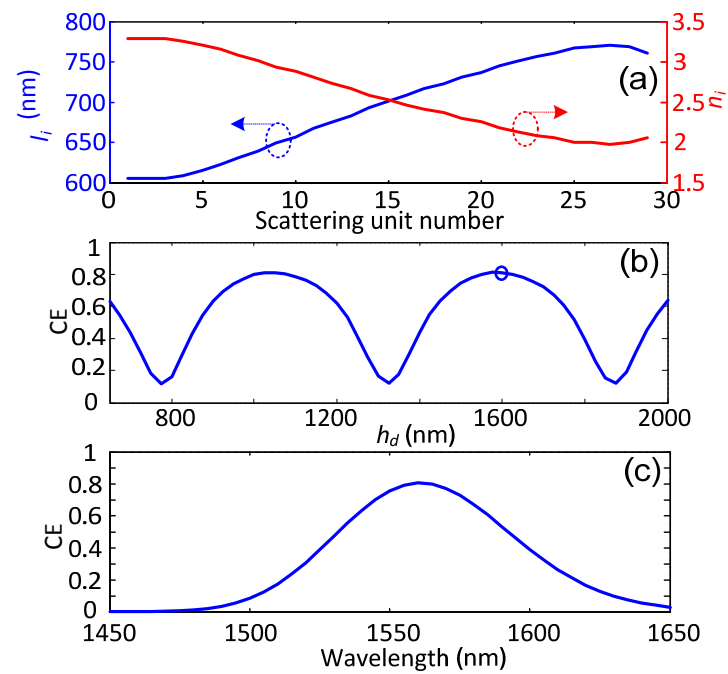

Fig. 3: (a) Designed $l_{i}$ and $n_{i}$ distributions of the grating couplers. Simulated coupling efficiency as a function of $(b)$ $h_{d}$, with $h_{u}=1000 \mathrm{~nm}$, and (c) wavelength, with $h_{d}=1600 \mathrm{~nm}$, and $h_{u}=1000 \mathrm{~nm}$.

respectively. A $100 \mathrm{~nm}$ titanium (Ti) mirror is introduced below the lower cladding. Another layer of $\mathrm{SiO}_{2}$ is introduced beneath the Ti mirror and is bonded to the silicon carrier wafer using a benzocyclobutene (BCB) layer. The coupling angle $\theta$ is designed to be $15^{\circ}$. The width of the artificial material slots is fixed to be $345 \mathrm{~nm}$, and the scattering strength and coupling angle are tuned by optimizing $n_{i}$ and $l_{i}$. The distributions of $n_{i}$ and $I_{i}$ of the grating coupler are designed, as shown in Fig. 3(a), so that a Gaussian output field profile with a beam radius of $5.2 \mu \mathrm{m}$ is synthesized from the grating with a coupling angle of $15^{\circ}$ at $1550 \mathrm{~nm}$. PhCs with triangular lattices can then be used for the artificial material slots, and the hole size for the PhCs can be determined by the effective index approximation ${ }^{9}$. The coupling efficiency of the transverse electric (TE) mode is then calculated by a $2 \mathrm{D}$ eigen-mode expansion method (EME) as a function of $h_{d}$ with $h_{u}$ set to $1000 \mathrm{~nm}$, as shown in Fig. 3(b). The coupling efficiency depends periodically on $h_{d}$, and reaches a local maximum at $h_{d}=1600 \mathrm{~nm}$. With $h_{d}=1600 \mathrm{~nm}$ and $h_{u}=1000 \mathrm{~nm}$, the coupling efficiency is then calculated as a function of wavelength, as shown in Fig. 3(c). A peak coupling efficiency of

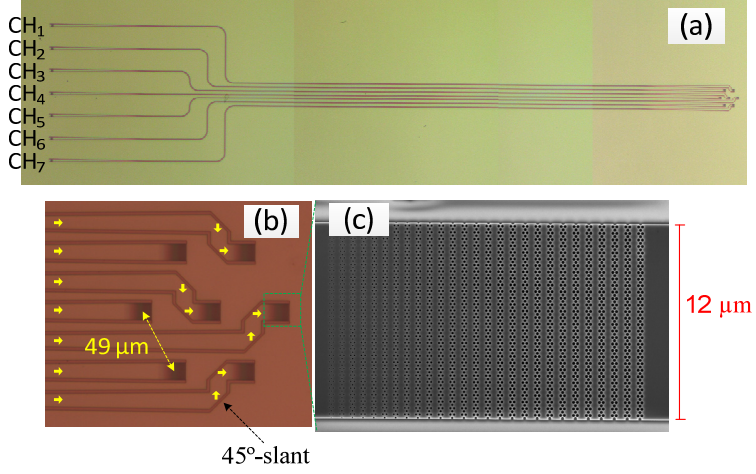

Fig. 4: (a) Fabricated device. (b) Details of the grating coupler array for directly coupling with a MCF. (c) Scanning electron microscopy (SEM) image of the apodized $\mathrm{PhC}$ grating coupler.

$81 \%$ (corresponding to $0.91 \mathrm{~dB}$ coupling loss) is predicted with a $3 \mathrm{~dB}$ bandwidth of $74 \mathrm{~nm}$.

\section{Device fabrication and characterization}

In order to validate our concept, the device was fabricated on a commercial SOI sample with top silicon thickness of $250 \mathrm{~nm}$ and buried silicon dioxide (BOX) of $3 \mu \mathrm{m}$. A single step of standard SOI processing, including e-beam lithography and inductively coupled plasma (ICP) etching was first used to fabricate the grating coupler and silicon waveguides simultaneously. An $800 \mathrm{~nm}$ thick layer of $\mathrm{SiO}_{2}$ was then deposited on top of the chip. Another $800 \mathrm{~nm}$ borophosphosilicate (BPSG) glass was deposited and annealed in nitrogen at $950^{\circ} \mathrm{C}$ for 30 minutes in order to planarize the chip surface. Afterwards, a $100 \mathrm{~nm}$ thick $\mathrm{Ti}$ layer was deposited on top of the BPSG. Then, about $2 \mu \mathrm{m}$ BCB layer was spun on both the sample and silicon carrier wafer. The sample was then flip-bonded on the silicon carrier wafer and thermally cured in an oven. Finally the substrate of the chip was removed by ICP fast etching.

Fig. 4 shows details of the fabricated device. The grating coupler is constructed by $\mathrm{PhC}$ based scattering slots with waveguide width of $12 \mu \mathrm{m}$, as shown in Fig. 4(c). The layout of the output grating couplers correspond to that of the cores of the MCF, with the same pitch of $49 \mu \mathrm{m}$, as shown in Fig. 4(a) and 4(b). In addition, 45slants with measured low insertion loss of

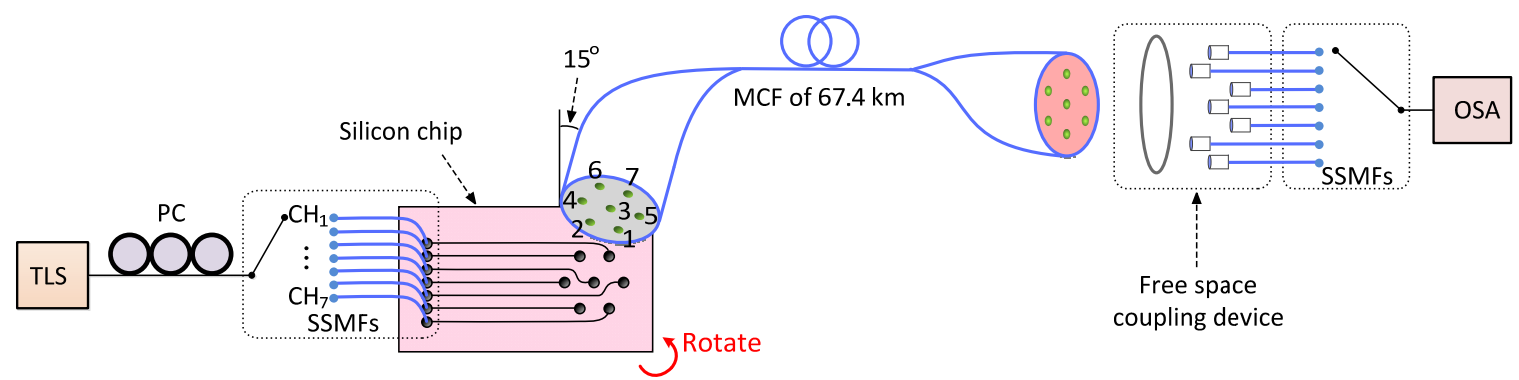

Fig. 5: Measurement setup of the grating coupler array-based on-chip MCF FI/FO. 
$0.05 \mathrm{~dB}$, are introduced to change the light beam propagation direction so that the $500 \mu \mathrm{m}$ long taper (from $12 \mu \mathrm{m}$ for the grating to $450 \mathrm{~nm}$ for the silicon single mode waveguide) can be placed outside the grating coupler array, as shown in Fig. 4(b).

The coupling loss from our device to an MCF with core pitch of $49 \mu \mathrm{m}$ and effective area of $110 \mu \mathrm{m}^{2}$ at $1550 \mathrm{~nm}$ was measured for each core. Fig. 5 shows the measurement setup. The device was mounted on a rotatable stage. Continuous wave $(\mathrm{CW})$ laser light from a tunable laser source (TLS) was polarization-tuned by a polarization controller $(\mathrm{PC})$, so that the light was launched to the input grating coupler on the TE mode. The MCF was mounted to a fiber holder with input angle of $15^{\circ}$. The stage was then horizontally rotated until all the grating couplers were well aligned with the corresponding cores of the MCF. The output of the MCF was spatially demultiplexed by a free space coupling device ${ }^{10}$, and the output power from each core was measured by an optical spectral analyzer (OSA). The coupling efficiency of the MCF FI/FO is shown in Fig. 6. It was obtained by subtracting the MCF transmission loss and free space coupling loss from the total link loss (from the grating coupler input to the free space coupling output). A lowest coupling loss of $6.8 \mathrm{~dB}$ with $3 \mathrm{~dB}$ coupling bandwidth of $48 \mathrm{~nm}$ and less than $3 \mathrm{~dB}$ coupling loss variation for the different spatial channels were measured. It should be noted that the coupling loss includes the loss of the input grating coupler, propagation loss along the silicon waveguides, insertion loss of the $45^{\circ}$ slant, and loss of the output grating coupler to the MCF. It should also be noted that our alignment method by rotating the stage will lead to non-optimum coupling angle for the MCF, resulting in larger coupling loss. Lower coupling loss can be expected by rotating the MCF instead. In addition, aluminum (Al) can be used instead of $\mathrm{Ti}$ for the back mirror to further reduce the coupling loss. Moreover, the effective area of $110 \mu^{2}$ of each fiber core is larger than that

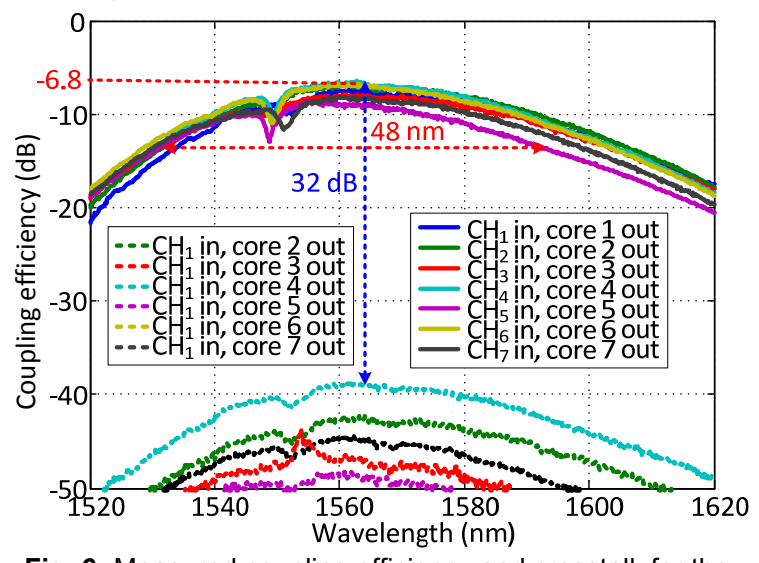

Fig. 6: Measured coupling efficiency and crosstalk for the MCF FI/FO. of an SSMF, for which the grating coupler was designed, which also results in higher coupling loss. Optimization of the output grating coupler can further reduce the total coupling loss. The crosstalk was also investigated by launching light into input $\mathrm{CH}_{1}$ and detecting light from the other non-corresponding cores (core 2 to 7 ) of the MCF. A low crosstalk of $-32 \mathrm{~dB}$ over a large bandwidth of $100 \mathrm{~nm}$ was measured, which is very close to a measured SMF to MCF crosstalk value of $-35 \mathrm{~dB}$ for the free space coupling device, indicating that the grating coupler array has very low crosstalk.

\section{Conclusions}

We have designed and demonstrated a compact MCF Fl/FO using a fully-etched grating coupler array on the SOI platform. A lowest coupling loss of $6.8 \mathrm{~dB}$ with $3 \mathrm{~dB}$ coupling bandwidth of $48 \mathrm{~nm}$ and less than $3 \mathrm{~dB}$ coupling loss variation between spatial channels were achieved.

\section{Acknowledgement}

This work is supported by the Danish Council for Independent Research (DFF-1337-00152 and DFF-1335-00771).

\section{References}

[1] T. Morioka, "New Generation Optical Infrastructure Technologies: "EXAT Initiative" Towards 2020 and Beyond," (invited) Proc. OECC, FT4, Hong Kong (2009).

[2] H. Takara et al., "1.01-Pb/s (12 SDM/222 WDM/456 Gb/s) Crosstalk-managed Transmission with $91.4-\mathrm{b} / \mathrm{s} / \mathrm{Hz}$ Aggregate Spectral Efficiency," Proc. ECOC, Th.3.C.1, Amsterdam (2012).

[3] B. Zhu et al., "Seven-core Multicore Fiber Transmissions for Passive Optical Network," Opt. Express, Vol. 18, p. 11117 (2010).

[4] T. Kobayashi et al., " $2 \times 344 \mathrm{~Tb} / \mathrm{s}$ Propagation-direction Interleaved Transmission Over 1500-km MCF Enhanced by Multicarrier Full Electric-field Digital BackPropagation," Proc. ECOC, PD3.E.4, London (2013).

[5] T. Mizuno et al., "12-core×3-mode Dense Space Division Multiplexed Transmission over $40 \mathrm{~km}$ Employing Multi-carrier Signals with Parallel MIMO Equalization," Proc. OFC, Th5B.2, San Francisco (2014).

[6] J. Sakaguchi et al., "19-core Fiber Transmission of $19 \times$ $100 \times 172-G b / s$ SDM-WDM-PDM-QPSK Signals at 305 Tb/s," Proc. OFC, PDP5C.1, Los Angeles (2012).

[7] R. R. Thomson et al., "Ultrafast Laser Inscription of a 121-waveguide Fan-out for Astrophotonics," Opt. Lett., Vol. 37, p. 2331 (2012).

[8] Y. Abe et al., "Low-loss Physical-contact-type Fan-out Device for 12-core Multicore Fiber," Proc. ECOC, P.1.7, London (2013).

[9] Y. Ding et al., "Ultrahigh-efficiency Apodized Grating Coupler Using Fully Etched Photonic Crystals," Opt. Lett., Vol. 38, p. 2732 (2013).

[10] W. Klaus et al., "Free-space Coupling Optics for Multicore Fibers," IEEE Photon. Technol. Lett., Vol. 24, p. 1902 (2012) 